\title{
Experimental study on ground vibration response in gun firing environment
}

\author{
Baoyuan Wang ${ }^{1}$, Qiang Lei ${ }^{2}$, Dongying Wang ${ }^{3}$ \\ Northwest Institute of Mechanical and Electrical Engineering, Xianyang, 712099, Shaanxi, China \\ ${ }^{1}$ Corresponding author

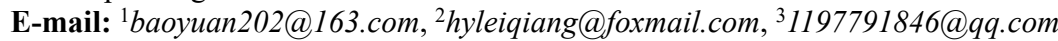

Received 20 July 2019; accepted 29 July 2019

DOI https://doi.org/10.21595/vp.2019.20917

Check for updates

Copyright (C) 2019 Baoyuan Wang, et al. This is an open access article distributed under the Creative Commons Attribution License, which permits unrestricted use, distribution, and reproduction in any medium, provided the original work is properly cited.

\begin{abstract}
In order to know the ground vibration response law of gun firing environment, a large caliber gun was taken as the research object, and the ground vibration response law of gun firing environment was tested. Several acceleration sensors are arranged on the ground around the gun, and the ground vibration acceleration response laws of the gun position in the firing environment are obtained. The firing of gun will cause the ground vibration of gun position. In the bore period, as long as the projectile is fired, there will be acceleration response on the ground of the gun position. The maximum acceleration response of ground vibration in the bore period of projectile is less than $0.03 \mathrm{~g}$. The maximum acceleration response of ground vibration is less than $0.1 \mathrm{~g}$ after projectile exits the muzzle and before the muzzle shock wave reaches the ground. If the sensor bracket is placed on the ground around the gun, when the muzzle shock wave does not reach the sensor position, the influence of ground vibration on the sensor can be neglected. Once the muzzle shock wave reaches the sensor position, its influence should be paid attention to.
\end{abstract}

Keywords: gun, firing, ground, vibration, test.

\section{Introduction}

The working characteristics of gun weapons are high temperature, high pressure, high speed and strong impact. When the gunpowder is ignited, it burns rapidly, and produces the high temperature and high pressure gunpowder gas, which drives the projectile to make intense acceleration movement in the bore until it flies away from the muzzle at high speed. Because of the strong excitation of gunpowder gas to the gun, the movement and force of the gun are very complex. The gun launching not only makes the gun produce strong translation, but also strong rotation, and accompanied by strong impact between various parts, the gun will produce very complex non-linear vibration. The whole working process of the gun is about ten milliseconds to several hundred milliseconds, which shows strong transient and randomness.

Gun is often deployed on the ground to shoot at enemy targets. The firing of gun will not only cause its own structural vibration, but also cause ground vibration. During the development of gun weapon, it is often necessary to test the vibration of gun structure. The test system is arranged on the ground to obtain the vibration response of gun structure relative to the ground. Then, what is the law of ground vibration caused by gun firing? What is the propagation law of ground vibration response of gun position? How much influence does it have on the gun vibration testing system? These problems have always been concerned by people in the process of gun weapon development. The so-called the ground of gun position is the ground around the gun.

Zhao Gang [1] carried out the research on the muzzle vibration test method of large caliber gun, using binocular vision test method based on the principle of high-speed camera, ignoring the influence of camera support stiffness, stability and ground vibration factors. Wang Hui [2] Aiming at the road spectrum acquisition test of gun during firing in travelling, a strapdown inertial navigation system (SINS) for road spectrum test was designed. In order to grasp the dynamic response law of self-propelled gun on typical soft ground, Liu Xinyun [3] carried out a simulation study on the dynamic response of self-propelled gun on soft-soil tire based on multi-body system 
dynamics software. Liu Chuan [4] analyzed the overall topological structure of a $122 \mathrm{~mm}$ vehicle-mounted howitzer. Considering the contact between tire and ground, a virtual prototype model of a $122 \mathrm{~mm}$ vehicle-mounted howitzer was built by ADAMS software. Du Zhonghua [5] carried out force analysis and simulation of the whole gun, analyzed in detail the recoil and recovery motion of the whole gun, and considered the interaction among the hoe, tire and ground. Liu Xinyun [6] based on multi-body system dynamics and vehicle ground mechanics, a self-propelled gun firing modeling and dynamic response research was carried out with the aid of analysis software, and a virtual prototype model of the moving, firepower and road surface parts of the equipment was established. Wang Baoyuan [7] summarized the mechanics model research of gun structure interface, and analyzed the contact characteristics tracked self-propelled gun between the track and ground, vehicle-mounted gun between the spade, pedestal and ground. Wang Baoyuan [8] laid instrument brackets on the ground to test the firing stability of gun. None of the above literatures deals with the experimental study of ground vibration response in gun firing environment.

In order to grasp the law of ground vibration response around gun in firing environment, taking large caliber gun as the research object, the experimental study on the law of ground vibration response of gun firing environment was carried out. Several acceleration sensors were arranged on the ground around gun, and the law of ground vibration acceleration response of gun position in firing environment was obtained, which provided basic data for the test data error analysis of gun vibration.

\section{Test principle}

Before gun firing, several measuring points are selected on the ground around the gun. Each measuring point is equipped with a acceleration sensor in the $50 \mathrm{~g}$ measurement range. The acceleration sensitive direction is vertical. In gun firing, the acceleration sensor senses the ground vibration acceleration response on the selected measuring point. At the end of firing, data processing is carried out to reveal the law of ground vibration. Fig. 1 is a sketch of the distribution of ground vibration acceleration measurement points. There are two distribution schemes. In the distribution 1, the accelerometer is located $2 \mathrm{~m}$ behind the muzzle, along the vertical direction of the barrel, on the side of the barrel, and the four accelerometers are spaced $1 \mathrm{~m}$ each. Sensor numbers are No. 1, No. 2, No. 3 and No. 4 in turn, in which sensor No. 1 is $2 \mathrm{~m}$ close to the barrel; In measurement point distribution 2, accelerometer is located $5 \mathrm{~m}$ behind muzzle, along the vertical direction of barrel, on the side of barrel. Four accelerometers are spaced $1 \mathrm{~m}$ each, and the arrangement of four sensors is similar to that of measurement point distribution 1 .

Firing conditions: The measuring point distribution 1 is flat angle firing, and the number of projectiles fired is 1 shot. The measuring point distribution 2 is 45 degree firing, and the numbers of projectiles fired are 5.

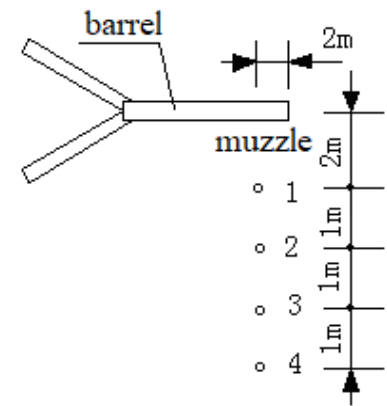

a) Point distribution 1

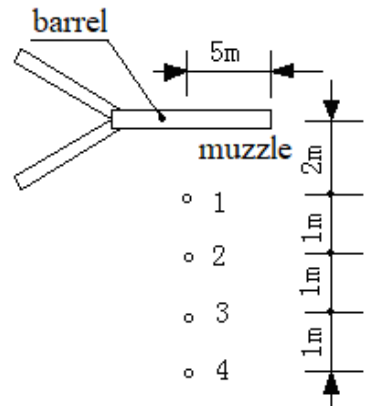

b) Point distribution 2

Fig. 1. Graphical distribution of the measurement points of the vibration acceleration on ground at gun position 
The time sensor is used to measure the projectile exit time. It is based on the principle of photoelectric conversion and uses the muzzle flame information to get the projectile exit time. The time sensor is arranged on the side of the gun, and the sensor is aimed at the muzzle. When the projectile exits the muzzle and the flame appears, a pulse signal appears in the time sensor to judge the time of the projectile exiting the muzzle.

\section{Research results}

Through acceleration test, the acceleration response curve and data results of the ground vibration around the gun selected under the firing conditions are obtained. Through data processing, the acceleration amplitude in bore, the initial response time of acceleration, the acceleration amplitude within $15 \mathrm{~ms}$ after projectile exit, and the start time of the significant change of acceleration response after projectile exit are obtained. Tables 1 and 2 are the acceleration response test data. Fig. 2 to Fig. 4 are the acceleration response test curves.

In Table 1, the following terms have the following meanings:

1) In-bore response time: the start time of the acceleration response in bore period of projectile;

2) Out-of-bore response time: the start time of acceleration response which significantly change after projectile exits muzzle;

3) In-bore acceleration: the acceleration amplitude in bore period of projectile;

4) Out-of-bore acceleration: the acceleration amplitude within 15 seconds after projectile exits muzzle.

The data in Table 1 are averaged and the results are shown in Table 2. In Fig. 2 to Fig. 4, the meanings of following symbols are:

1) $a$ : the acceleration of ground vibration in gun position, unit, g;

2) $T$ : the time signal of projectile exit muzzle, unit, $\mathrm{V}$;

3) $a_{1}$ : the acceleration of ground vibration of the gun position in point No. 1, unit, g;

4) $a_{2}$ : the acceleration of ground vibration of the gun position in point No. 2, unit, g;

5) $a_{3}$ : the acceleration of ground vibration of the gun position in point No. 3, unit, g;

6) $a_{4}$ : the acceleration of ground vibration of the gun position in point No. 4, unit, g;

7) $t_{1}$ : the moment of projectile exits muzzle;

8) $t_{2}$ : the starting time of acceleration response in the bore of projectile;

9) $t_{4}$ : the starting time of acceleration response which significantly change after projectile exits muzzle (measurement point distribution 2).

The results show that the acceleration response of the ground vibration of the gun position, flat angle firing and 45 degree angle firing for gun selected, will occur as soon as the projectile is fired in the bore, and the maximum acceleration response in the bore is $0.03 \mathrm{~g}$ (measuring point distribution 1) and $0.02 \mathrm{~g}$ (measuring point distribution 2). After the projectile exits the muzzle, after $6.06 \mathrm{~ms}$ (measuring point distribution 1) and $17.0 \mathrm{~ms}$ (measuring point distribution 2), the ground vibration acceleration response begins to change significantly, and then the acceleration exceeds the sensor range. For the measurement point distribution 1, the begining time of acceleration response changing significantly of ground vibration is short, which is due to the fact that the sensor is close to the muzzle and the muzzle shock wave reaches a short time. The maximum ground vibration acceleration response is $0.1 \mathrm{~g}$ (measuring point distribution 1) and $0.09 \mathrm{~g}$ (measuring point distribution 2) from the time when the projectile exits the muzzle to the time when the acceleration response begins to change significantly. The farther away from the barrel, the longer the acceleration response time increases sharply. The reason is that the propagation time of ground vibration becomes longer gradually. After projectile exits the muzzle, the significant change of acceleration response is caused by the muzzle shock wave impacting the acceleration sensor on the ground, not the ground vibration acceleration response value. When the muzzle shock wave reaches the position of the accelerometer, the accelerometer will exceed the range.

If the sensor bracket is placed on the ground around the gun, when the muzzle shock wave 
does not reach the sensor position, its acceleration response maximum is only $0.1 \mathrm{~g}$. The influence of ground vibration on the sensor can be neglected. Once the muzzle shock wave reaches the sensor position, its influence should be paid attention to.

Table 1. Testing results of ground vibration acceleration at gun position

\begin{tabular}{|c|c|c|c|c|c|c|}
\hline & Measuring point & 1 & 2 & 3 & 4 & Average \\
\hline \multirow{4}{*}{$\begin{array}{c}\text { Shot No. 1 } \\
\text { (distribution 1) }\end{array}$} & In-bore response time / $\mathrm{ms}$ & 23.7 & 23.7 & 23.7 & 23.7 & 23.70 \\
\hline & Out-of-bore response time / $\mathrm{ms}$ & 4.99 & 5.58 & 6.59 & 7.07 & 6.06 \\
\hline & In-bore acceleration / g & 0.03 & 0.06 & 0.02 & 0.01 & 0.03 \\
\hline & Out-of-bore acceleration / g & 0.10 & 0.38 & 0.06 & 0.06 & 0.15 \\
\hline \multirow{4}{*}{$\begin{array}{c}\text { Shot No. 2 } \\
\text { (distribution 2) }\end{array}$} & In-bore response time / $\mathrm{ms}$ & 29.52 & 29.52 & 29.52 & 29.52 & 29.52 \\
\hline & Out-of-bore response time / ms & 16.5 & 16.5 & 17.34 & 18.44 & 17.20 \\
\hline & In-bore acceleration / g & 0.02 & 0.02 & 0.01 & 0.04 & 0.02 \\
\hline & Out-of-bore acceleration / g & 0.12 & 0.06 & 0.04 & 0.06 & 0.07 \\
\hline \multirow{4}{*}{$\begin{array}{c}\text { Shot No. } 3 \\
\text { (distribution 2) }\end{array}$} & In-bore response time / ms & 30.6 & 30.6 & 30.6 & 30.6 & 30.60 \\
\hline & Out-of-bore response time / $\mathrm{ms}$ & 16.08 & 16.08 & 16.97 & 18.39 & 16.88 \\
\hline & In-bore acceleration / g & 0.03 & 0.02 & 0.01 & 0.04 & 0.03 \\
\hline & Out-of-bore acceleration / g & 0.14 & 0.07 & 0.04 & 0.1 & 0.09 \\
\hline \multirow{4}{*}{$\begin{array}{c}\text { Shot No. } 4 \\
\text { (distribution 2) }\end{array}$} & In-bore response time / $\mathrm{ms}$ & 30 & 30 & 30 & 30 & 30.00 \\
\hline & Out-of-bore response time / $\mathrm{ms}$ & 16.21 & 16.21 & 16.96 & 18.02 & 16.85 \\
\hline & In-bore acceleration / g & 0.02 & 0.03 & 0.01 & 0.04 & 0.03 \\
\hline & Out-of-bore acceleration / g & 0.10 & 0.07 & 0.06 & 0.23 & 0.12 \\
\hline \multirow{4}{*}{$\begin{array}{c}\text { Shot No. } 5 \\
\text { (distribution 2) }\end{array}$} & In-bore response time / $\mathrm{ms}$ & 28.61 & 28.61 & 27.22 & 27.22 & 27.92 \\
\hline & Out-of-bore response time / $\mathrm{ms}$ & 16.14 & 16.32 & 17.28 & 18.76 & 17.13 \\
\hline & In-bore acceleration / g & 0.03 & 0.02 & 0.01 & 0.03 & 0.02 \\
\hline & Out-of-bore acceleration / g & 0.1 & 0.09 & 0.06 & 0.16 & 0.10 \\
\hline \multirow{4}{*}{$\begin{array}{c}\text { Shot No. } 6 \\
\text { (distribution 2) }\end{array}$} & In-bore response time / ms & 30.06 & 30.06 & 30.06 & 30.06 & 30.06 \\
\hline & Out-of-bore response time / ms & 16.05 & 16.39 & 16.91 & 18.52 & 16.97 \\
\hline & In-bore acceleration / g & 0.02 & 0.03 & 0.01 & 0.02 & 0.02 \\
\hline & Out-of-bore acceleration / g & 0.12 & 0.07 & 0.05 & 0.12 & 0.09 \\
\hline
\end{tabular}

Table 2. Statistical results of ground acceleration test at gun position

\begin{tabular}{|c|c|c|c|c|}
\hline Distribution mode & $\begin{array}{c}\text { In-bore response } \\
\text { time / } \mathrm{ms}\end{array}$ & $\begin{array}{c}\text { Out-of-bore } \\
\text { response time / } \mathrm{ms}\end{array}$ & $\begin{array}{c}\text { In-bore } \\
\text { acceleration /g }\end{array}$ & $\begin{array}{c}\text { Out-of-bore } \\
\text { acceleration / g }\end{array}$ \\
\hline Distribution 1 & 23.7 & 6.06 & 0.03 & 0.10 \\
\hline Distribution 2 & 29.62 & 17.00 & 0.02 & 0.09 \\
\hline
\end{tabular}

In Fig. 2 to Fig. 4, from top to bottom, the curves are the muzzle signal, the acceleration of No. 1, No. 2, No. 3 and No. 4 measuring points, respectively. In Fig. 2, the maximum acceleration values of No. 1, No. 2, No. 3 and No. 4 measuring points are $0.05 \mathrm{~g}, 0.09 \mathrm{~g}, 0.03 \mathrm{~g}$ and $0.02 \mathrm{~g}$ respectively in the period of projectile bore. Except for No. 1 measuring points, the acceleration decreases with the distance of the measuring point from the barrel. In Fig. 3, after the projectile exits the muzzle, the corresponding times for the acceleration to increase sharply are $2.26 \mathrm{~ms}$, $5.67 \mathrm{~ms}, 8.61 \mathrm{~ms}$ and $11.37 \mathrm{~ms}$, respectively. The farther away from the barrel, the longer the acceleration increases sharply. The reason is that the propagation time of ground vibration becomes longer gradually. In bore period of projectile, the acceleration amplitudes of No. 1, No. 2, No. 3 and No. 4 measuring points are $0.01 \mathrm{~g}, 0.01 \mathrm{~g}, 0.01 \mathrm{~g}$ and $0.04 \mathrm{~g}$, respectively.

When firing at flat angle, the muzzle is very close to the ground, and the muzzle shock wave is strong. When the muzzle shock wave reaches the position of the sensor, the maximum acceleration of sensor bracket is far beyond the range of $50 \mathrm{~g}$ of the accelerometer. When firing at high angle, the maximum acceleration of the whole firing process is about $50 \mathrm{~g}$. 


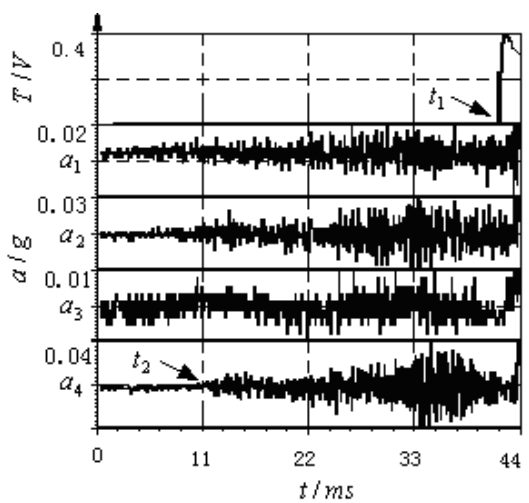

Fig. 2. Acceleration test curves of ground (in bore period, distribution 2)

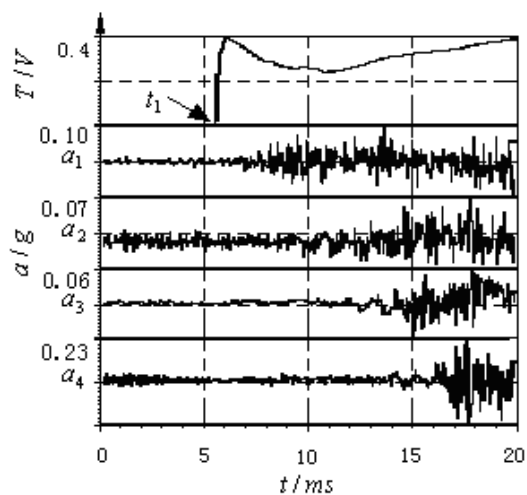

Fig. 3. Acceleration test curves of ground (within $15 \mathrm{~ms}$ after projectile exit $15 \mathrm{~ms}$ )

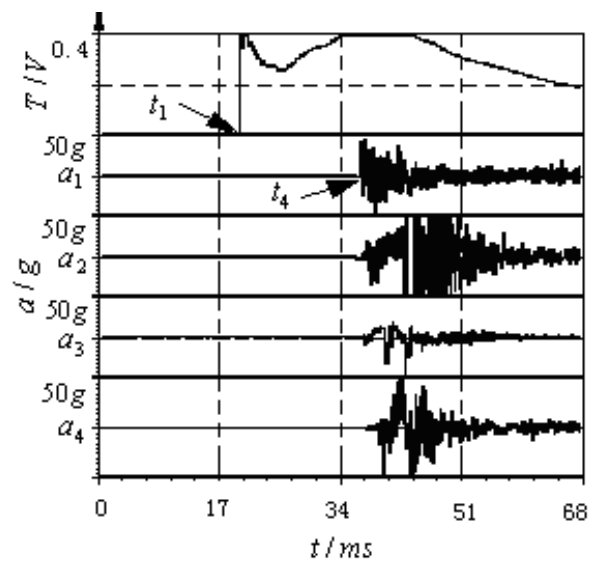

Fig. 4. The acceleration test curves of gun position ground (whole firing process, measuring point distribution 2)

\section{Conclusions}

The firing of gun will cause the ground vibration of the gun position. In the interior period of the projectile, as long as the projectile is fired, there will be vibration acceleration response on the ground of the gun position. Before the muzzle shock wave reaches the ground, the maximum acceleration response on ground in bore is less than $0.03 \mathrm{~g}$. From the projectile's exit to the shock wave's arrival at the ground, the maximum acceleration response on ground is $0.1 \mathrm{~g}$. The output values of accelerometer arranged on the ground will increase rapidly after the projectile exits the muzzle and after the muzzle shock wave reaches the ground. The rapid increase of the output values of the accelerometer is caused by the muzzle shock wave impacting the accelerometer on the ground, not the response value of the ground vibration acceleration.

If the sensor bracket is placed on the ground around the gun, when the muzzle shock wave does not reach the sensor position, the maximum ground acceleration is only $0.1 \mathrm{~g}$, and the influence of ground vibration on the sensor can be neglected. Once the muzzle shock wave arrives at the sensor position, the acceleration of the sensor support will increase rapidly, so its influence should be paid attention to.

\section{References}

[1] Zhao Gang Research on measuring method of large-caliber gun muzzle vibration. Nanjing University, Nanjing, 2015, (in Chinese). 
[2] Wang Hui Srapdown innertial navigation system design for road spectrum measurement. Harbin Institute of Technology, Harbin, 2009, (in Chinese).

[3] Liu Xinyun, Ma Jisheng, Wang Wei, et al. Self-propelled gun dynamic response simulation research based on the soft-soil tire. Journal of Gun Launch and Control, Vol. 38, Issue 3, 2017, p. 25-30, (in Chinese).

[4] Liu Chuan, Xue Deqing, Jia Changzhi, et al. Study on effect of tire to firing stability of truck-mounted gun. Fire Control and Command Control, Vol. 42, Issue 3, 2017, p. 70-74+79, (in Chinese).

[5] Du Zhonghua, Huang Tao, Wu Dalin Analysis and simulation of bear forces for whole gun. Mechanics, Vol. 41, Issue 8, 2014, p. 45-49, (in Chinese).

[6] Liu Xinyun, Ma Jisheng, He Jian, et al. Modelling and dynamic response of a self-propelled gun firing on the move. Journal of Gun Launch and Control, Vol. 37, Issue 3, 2016, p. 6-10+16, (in Chinese).

[7] Wang Baoyuan, Dong Wenxiang, Shao Xiaojun Review and prospect of the research on the gun structure joint surfaces in mechanical model (II). Journal of Gun Launch and Control, Vol. 32, Issue 4, 2011, p. 90-93, (in Chinese).

[8] Wang Bao Yuan, Heng Gang, Zhou Fa Ming, et al. Progresses of a measurement technology of gun. National Defense Industry Press, Beijing, 2011, p. 160-173, (in Chinese). 